\title{
Application of Radio Frequency Identification (RFID) in Science Education
}

\author{
Xiao Huang, Yau Yuen Yeung, Siu Cheung Kong, and Wei Gao
}

\begin{abstract}
Two application aspects of radio frequency identification (RFID) technology in science education are given. First, RFID technology contributes in carrying out scientific inquiry at all levels; taking "the classification of plants" as an example, we put forward that the application of RFID is conducive in creating individual situational scientific inquiry and that it provides students with multidimensional ways of cooperation and interaction. In addition, it contributes to the integration of formative assessment and summative evaluation. Second, RFID technology provides a way for students to understand the nature of science; the example of "plants classification" shows the relationship between science inquiry and the nature of science. Taking the "pendulum" as another example, we propose that RFID technology helps students in understanding the nature of science.
\end{abstract}

Index Terms-RFID, science education, scientific inquiry, nature of science

\section{INTRODUCTION}

With the development of radio frequency identification (RFID) technology in the field of education in Hong Kong and Taiwan, it has become necessary for us to reflect on the meaning and value of RFID in education [1]. Particularly, several research on such technology has been done, which marked the further development of RFID and its application, from tools to resource-based transformation. Among these are the "China Radio Frequency Identification (RFID) Technology Policy White Paper" [2], which was published by the Ministry of Science and Technology on June 9, 2006, and the "RFID Blue Book - Report on the RFID Development and Its Application in China" [3], which was published in Shanghai Zhangjiang on November 3, 2009. The publication of both books marked the further development of RFID and its application from the tools to the resource-based

Manuscript received August 30, 2011. This work was supported in part by the Zhejiang Provincial Education Department of China (Y201018272) and the Croucher Foundation of Hong Kong.

Xiao Huang is with the Physics Department of East China Normal University, Shanghai, 200062, and the Department of Education, Zhejiang Normal University, Zhejiang, Jinhua 321004, P.R. China. (e-mail: huangxiao@zjnu.cn)

Yau-yuen YEUNG is with the Department of Science and Environmental Studies, Hong Kong Institute of Education, Lo Ping 10, Tai Po, New Territories, Hong Kong. (Email:yyyeung@ied.edu.hk)

Siu Cheung KONG is with the Department of Mathematics and Information Technology, the Hong Kong Institute of Education, Lo Ping 10, Tai Po, New Territories, Hong Kong. (E-mail:sckong @ied.edu.hk)

Wei Gao is with the Department of Information, Yunnan Normal University, Yunnan, Kunming, 650092, P.R. China. Also he is PhD student in the Department of Mathematics, Soochow University, Jiangsu, Suzhou, 215006, P.R. China. (E-mail: gaowei@ynnu.edu.cn). transformation. The great debate on RFID in the fields of manufacturing, information technology, logistics, and intelligent transportation network prompts us to examine the benefits RFID could bring to science education.

\section{COMPOSITION AND CHARACTERISTICS OF RFID TECHNOLOGY}

RFID technology is a broad concept, which has different types but basically the same composition - the reader, RFID application system and the electric tag usually including antennas, modulation, coding and storage devices, etc. the tags, which store with the object-related information, are placed on the object to be identified. The readers, which contain the antenna, RF module, control processing module, transfer data between electronic tags through the air interface - reader sends commends to the tag, and then the tag make the appropriate response. In addition to the data communication, the reader sends the collected tag data to the back-end applications through Application Program Interface (API), namely to achieve the data read. For read-write RFID systems, reader can receive the commands by API and write information about data into tag. RFID should follow the prescribed protocol (such as ISO14443, ISO15693, etc.) and standards (such as EPC standards, etc.), which is mainly reflected in the API - show by a set of standard interface functions composed of the application development tools (such as $\mathrm{VC}++, \mathrm{VB}, \mathrm{C} \#, \mathrm{C}$, etc.).

1. Automatic Identification - RFID technology transfer data through non-contact information transmission between the reader and tag. Regardless of close range RFID system which transferred data by load modulation or long-range RFID system which transferred data by backscatter, can be identified and automatically obtain information about the identified items, and then provide the data to computer processing system[4]. Contrast other automatic identification technologies (bar code technology, optical recognition technology, voice recognition, biometrics, magnetic cards, contactless IC card), RFID shows the characteristics: (1) EEPROM is the information carrier which can store large capacity.(2)with high speed of read and write by wireless communication.(3)identification without direct contact, reading not affected by the location and environment. (4) Memory has a unique serial number that can uniquely identify objects, locations. (5) With anti-collision function which can read multiple tags at the same time.

2. Short-range wireless communications - compare with long-range wireless communications, RFID technology is a short-range wireless communication technology, mainly 
characterized by the wireless transmit power is typically less than $100 \mathrm{~mW}$, the communication distance is generally a few centimeters to several hundred meters, which is used in the house[5]. RFID technology own the same transmit features with the emerging variety short-range wireless communication protocols - such as NFC (Near Field Communication), Bluetooth, ZigBee, WiFi, UWB (Ultra WideBand), DSRC (Dedicated Short Range Communication). The distance for RFID automatic identification depends on the interface distance ( $0-1 \mathrm{~cm}$ for close-coupled type, less than one meter for remote coupling, typically there are two types of $15 \mathrm{~cm}$ and $1 \mathrm{~m} ; 1-10 \mathrm{~m}$ for long range coupling) and frequency (commonly $125 \mathrm{kHz}$ for low frequency, $13.56 \mathrm{MHz}$ for high frequency, $900 \mathrm{MHz}$ and $2.4 \mathrm{GHz}$ for UHF). RFID technology enables real-time dynamic communication, such as communicate information by $0.02-0.01 \mathrm{~ms}$ for each tag and can be dynamically tracking and monitoring.

3. Features of RFID with different frequency ${ }^{1}-$ Frequency $^{-}$ are an important parameter, which largely determine the application scope, technical feasibility and the level of system cost of RF tag, and then determine the application scope. Table 1 shows the application of different RFID application from the reading distance, chip memory, transmission power and features.

TABLE I. COMPARISON FEATURES OF DIFFERENT FREQUENCY RFID SYSTEM

\begin{tabular}{|c|c|c|c|}
\hline & $\begin{array}{r}\text { Low- } \\
\text { frequency }\end{array}$ & \multicolumn{2}{|c|}{ High-frequency } \\
\hline $\begin{array}{l}\text { Frequency } \\
\text { band }\end{array}$ & $30-300 \mathrm{kHz}$ & \multicolumn{2}{|l|}{ 3-30MHz } \\
\hline \multirow{2}{*}{$\begin{array}{l}\text { Reading } \\
\text { distance }\end{array}$} & \multirow{2}{*}{$0-0.5 \mathrm{~m}$} & ISO14443 & ISO15693 \\
\hline & & $<0.5 \mathrm{~m}$ & $<1.5 \mathrm{~m}$ \\
\hline $\begin{array}{l}\text { Chip } \\
\text { memory }\end{array}$ & $64 \mathrm{~B}-2 \mathrm{~KB}$ & $8 \mathrm{~KB}-128 \mathrm{~KB}$ & $256-512 B$ \\
\hline $\begin{array}{l}\text { Transmit } \\
\text { power }\end{array}$ & $72 \mathrm{~dB} \mu \mathrm{A} / \mathrm{m}$ & \multicolumn{2}{|l|}{$42 \mathrm{~dB} \mu \mathrm{A} / \mathrm{m}$} \\
\hline features & $\begin{array}{l}\text { Not sensitive, } \\
\text { with good } \\
\text { ability to read } \\
\text { in metal or } \\
\text { liquid } \\
\text { (moisture) } \\
\text { environment } \\
\text { With low power } \\
\text { consumption } \\
\text { because of low } \\
\text { clock frequency }\end{array}$ & \multicolumn{2}{|c|}{$\begin{array}{l}\text { The reading distance is reduced } \\
\text { because of the signal attenuation } \\
\text { (electromagnetic energy is reflected) } \\
\text { for metal materials. With poor } \\
\text { reading ability in metal and liquid } \\
\text { (moisture) environment. High clock } \\
\text { frequency enables the password } \\
\text { function, microprocessor and } \\
\text { resonance is true. } \\
\text { Use ISO14443A/B - ISO15693 } \\
\text { ISO18000-3 }\end{array}$} \\
\hline
\end{tabular}

\footnotetext{
${ }^{1}$ RFID has different categories based on different technology features. It can be divided into active, passive and semi- active three kinds by energy supply means. It can be divided into low frequency $(30-300 \mathrm{kHz})$, high frequency (3-30MHz), UHF (300-968MHz), and microwave (2.45-5.8GHz), mixing (more than two frequencies) system by frequency. It can be divided into read-only (RO), read-write (RW) and write once read (WORM) by read-write features. It can be divided into RFI and TTF (passive tags generally use TTF) by timing of work, and so on. [6]

${ }^{2} \mathrm{High}$ frequency $(13.56 \mathrm{MHz}) \mathrm{RFID}$ system uses three main international standards, which are two commonly used standards are ISO14443A/B or ISO15693. There are some differences of two standards, such as the reading distance of ISO14443 (less than 10cm) is less than ISO15693 (less than $100 \mathrm{~cm}$ ). There are two kinds of modulation in different ways for ISO14443, 100 percent of ASK modulation for ISO14443A, 10 percent of ASK modulation (from reader to tag) and BPSK (phase) modulation (from tag to reader) for ISO1443B, while ISO15693 with 10 percent or 100 percent of ASK modulation, etc.
}

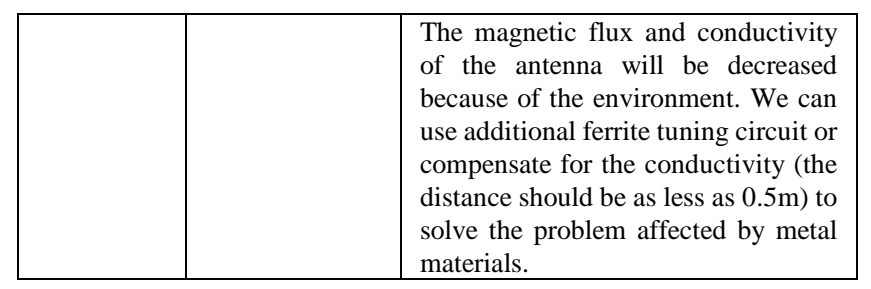

\begin{tabular}{|c|c|c|c|}
\hline & Ultra-high frequency & \multicolumn{2}{|c|}{ Micro-wave } \\
\hline $\begin{array}{l}\text { Frequency } \\
\text { band }\end{array}$ & $100-968 \mathrm{MHz}$ & \multicolumn{2}{|c|}{$2.45-5.8 \mathrm{GHz}$} \\
\hline \multirow{2}{*}{$\begin{array}{l}\text { Reading } \\
\text { distance }\end{array}$} & passive & active & $\begin{array}{l}\text { passiv } \\
\text { e }\end{array}$ \\
\hline & $3-10 \mathrm{~m}$ & $3-10 \mathrm{~m}$ & $>10 \mathrm{~m}$ \\
\hline $\begin{array}{l}\text { Chip } \\
\text { memory }\end{array}$ & $64-512 B$ & 16-64B & \\
\hline $\begin{array}{l}\text { Transmit } \\
\text { power }\end{array}$ & $10 \mathrm{~mW}-4 \mathrm{~W}$ & \multicolumn{2}{|c|}{$\begin{array}{l}\text { 4W(USA)/500mW(Eur } \\
\text { ope) }\end{array}$} \\
\hline \multirow[t]{2}{*}{ features } & 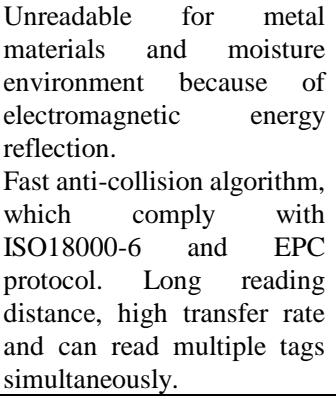 & \multicolumn{2}{|c|}{$\begin{array}{l}\text { Unreadable for metal } \\
\text { materials and moisture } \\
\text { environment because of } \\
\text { electromagnetic energy } \\
\text { reflection. } \\
\text { Less subject to strong } \\
\text { electromagnetic } \\
\text { interference, the size of } \\
\text { label can be small, but } \\
\text { the cost is too high. }\end{array}$} \\
\hline & \multicolumn{3}{|c|}{$\begin{array}{l}\text { The magnetic flux and conductivity of the antenna will be } \\
\text { decreased because of the environment. We can use } \\
\text { additional ferrite tuning circuit or compensate for the } \\
\text { conductivity (the distance should be as less as } 0.5 \mathrm{~m} \text { ) to } \\
\text { solve the problem affected by metal materials. }\end{array}$} \\
\hline
\end{tabular}

\section{RFID TEChNOLOGY Is CONDUCIVE To The CONDUCT OF SCIENTIFIC INQUIRY}

Understanding scientific inquiry should be based on the cognition of "what science is". A review of the history of science and technology development would show us that the process by which human learn about "science" can be divided into four stages [7]: science is equivalent to the "rational freedom" or the empirical inquiry science; science is the "truth"; science is "to explore and experiment"; and science is a dynamic situation, which is supported by evidence. The understanding of "science" as "public science" or "popular science" is the interpretation of the evidence-based view of science, which gives new meaning to scientific inquiry. Scientific inquiry is not only limited to the means by which scientists study nature to gain evidence in support of an idea and explain their findings; it also refers to the process by which students acquire knowledge, comprehend the ideas proposed by scientists, and understand the methods used in studying nature [8]. Inquiry skills are correlated to the context, which is complex and diverse. Scientific inquiry processes embody the individual's uniqueness, reflect its sociality, and provide collective knowledge creation. Hence, providing students with specific problem situation is prerequisite to effective inquiry.

Unlike other automatic identification technologies (bar code technology, optical recognition technology, voice recognition, biometrics, magnetic card, and contact Identify card) RFID not only has high-speed recognition, large storage 
capacity, and the unique capability of having strong adaptability to the environment (e.g., low-frequency RFID could still read even in liquid and metal), but it can also read multiple tags at the same time, which is referred to as its anti-collision property. As a short-range communication technology, RFID can achieve a $0.02-0.01 \mathrm{~ms}$ for each tag rate to communicate data and information with a reader. In the readable scope, RFID can dynamically track and monitor tags' location, which embodies the characteristic of real-time dynamic. RFID technology can promote the development of scientific inquiry for the following reasons:

(1) To promote personalized scientific inquiry context creation - The information of RFID reader and tag can communicate the read and write commands of the application system to the electronic tags and can also return data decryption evacuation back to the application system. The application system can be connected to a computer as needed or to a PDA and then assign the network connection according to the storage capacity and the need. The application system can provide students with real-time, life-related social and technical problem situations, which would give them the opportunity to explore the understanding of science. At the same time, students' learning activities can be recorded through the RFID system in real time, thereby providing them information for inquiry according to their personal needs; this indicates that the context for every student's scientific inquiry is personalized.

(2) To provide students with multidimensional cooperation approaches - The connection of RFID reader to network makes the communication and cooperation from different geographic locations possible. They can revolve a task with a common degree of interest, and design and complete a program through consultation with one another cooperation, and interactive discussions, which reflect the richness, flexibility, and diversity of cooperation and interaction. Each student can choose his own partners in developing an effective cooperative learning according to his learning styles, time, and space.

(3) To promote the effective attainment of formative assessment - The evaluation of scientific inquiry should focus on the process of evaluating students' learning activities. Due to it is important to examine students' final results, we should pay attention to students' performance in the implementation process of observation and analysis. RFID technology can be used for real-time recording and tracking of the learning process, which comprises real-time records of learners and their partners' learning process such as experience, debate, cooperation, competition, problem solving, and other learning experiences. It is helpful to objectively evaluate the students using experimental apparatus, such as the accuracy of laboratory equipment selection and the specification of using the apparatus. It also helps to evaluate students based on their active participation and cooperation, such as exploring whether the problem is clear or the program is reasonable. The capability of RFID for real-time recording makes the combination of process evaluation and result evaluation possible.

There are various levels of scientific inquiry. On the one hand, it embodies the difference in the objects, methodologies, and results of scientific inquiry for scientists and students. On the other hand, it shows the different levels of scientific investigations for different grade levels of students ${ }^{3}$. RFID technology is conducive to the conduct of scientific inquiry activities. An example would be kindergarten students combining playing with learning, in which RFID technology provides a visual, auditory, and other multidimensional feel-phase play situations in order for students to gain emotional and intuitive understanding of a phenomenon. With regard to graduate students, scientific inquiry is considered as "students' study exploration", wherein the communication between adaptable partners helps in developing ideas, while RFID technology provides diverse and flexible forms of cooperation.

We take "the classification of plants" as an example to explain the RFID technology application in scientific inquiry activities. The reader used in the example, called S8-A reader, was manufactured by Shenzhen Peak Company and has an operating frequency of $13.56 \mathrm{MHz}^{4}$; it can read and write Mifare S50, S70, and ultra light chip. Attached to the label on each plant were used stickers shaped as Mifare $550^{5}$. The application system use VB language for second development due to the teaching process, and teaching activities were carried out in groups.

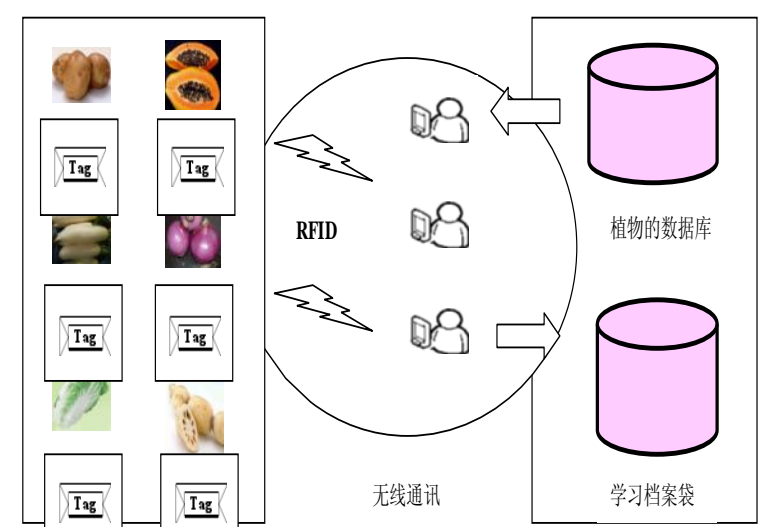

Fig. 1.Schematic of RFID technology in "the classification of plants" teaching activities

${ }^{3}$ Gaoxia proposes five categories of scientific inquiry according to the extent of guidance of a science teacher, which actually shows the different levels of scientific inquiry activities [9]

${ }^{4}$ Because the reading distance of low-frequency-based RFID is minor and is affected by the direction of the antenna, readers and applications often only support the RS232 serial communication or the interface with USB and data can be read directly into the computer's documents (but it cannot connect to PDA). While students' exploration often occurs within the classroom in general, and although we used multiple readers with anti-collision capabilities placed in an area not too far, the accurate reading of particular information will be affected. Also, low-frequency RFID is often only read, not write, which in some extent limits students' communication, cooperation, and evaluation activities in the process of problem solving. Thus, we should use high-frequency RFID.

${ }^{5}$ It is more convenient in practical applications to use high-frequency (13.56 MHz) with a CF or SD interface readers or connect to PDA, but the cost is higher. The $\mathrm{CF}$ interface reader is consistent with two kinds of international standards, which support ISO14443A, ISO14443B, and ISO15693 (such as the KD801CF reader of Beijing Sum Co., Ltd and the CF RFID reader of Guangzhou Far East Co., Ltd.), and can connect to notebook with CF card, PDA, and smart phone (we used the HP PDA), which supports Microsoft Pocket PC 2002/2003, Windows Mobile 5.0/6.0, Windows CE4.2/5.0 operating system, and Windows 98/XP/Visa. The information from RFID tags read by a CFRD card can be communicated with WiFi, CDMA, GSM, Bluetooth, and other devices. 
Figure 1 shows the schematic to carry out "the classification of plants" by RFID technology. One card-like tag Mifare S50 is used to record the students' involvement in the learning process and which store the students' learning as portfolio.

The inquiry activities include two facts - regard the inquiry of RFID characteristic based on students' experience as the beginning, use RFID technology to classify the plants. As to the RFID characteristic cognition, we encourage students to find RFID features by many questions. For example, why the shell of RFID reader and tag are both made by plastic? Both RFID reader and tag have antenna and chip, what is the different and reason for different inference? The dimensions and questions which can be inquiry are shown in Table2. In this activity, students are encouraged to use implement (such as oscilloscope) know Sense range, sense effects with the materials and distance (Figure 2).

TABLE II. RFID FEATURES TO INQUIRY

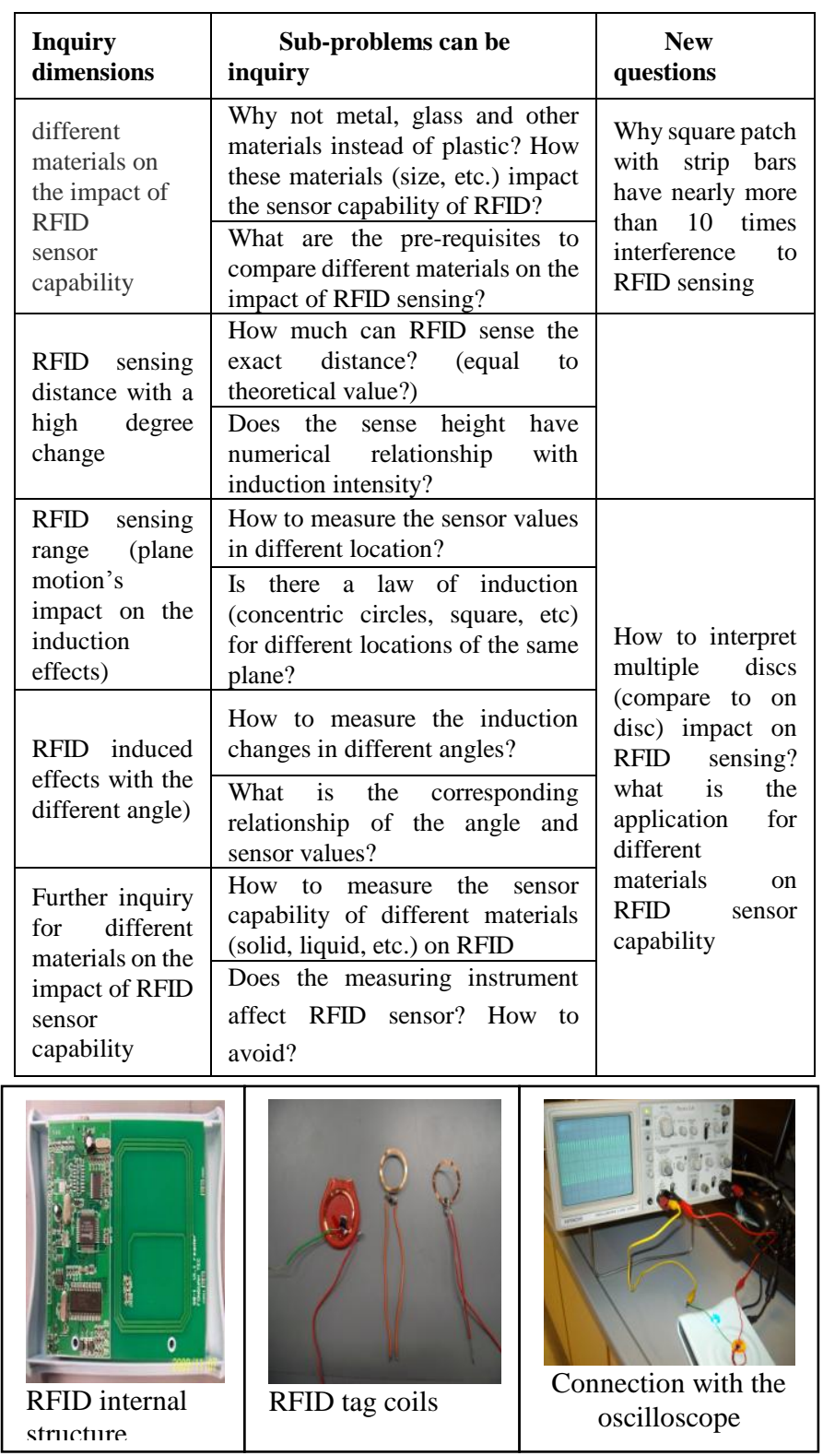

Fig. 2. Activities can be inquired

Each team has four S8-A readers, and each plant is given a label. The use of RFID technology keeps the plants in the database for the extraction of the required information provided for students to explore. The exploration activities are divided into three steps:

(1) Recognizing the variety of plants - When various plants are recognized by the RFID reader antenna field sensor, the reader connected to the database can provide students with information about the plant (the condition for plant growing, plant morphology, medicinal functionality, features, and food culture). Figure 3 shows a record of one student picking a cantaloupe; the reader can provide relevant information about the fruit through the database.

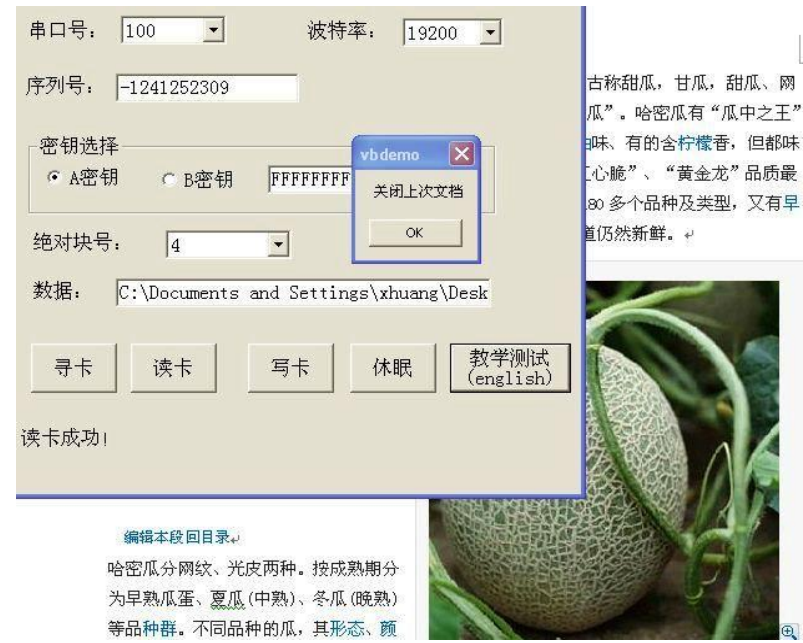

Fig. 3. Information provided by database when a student picks a cantaloupe

(2) The various categories of plants - Students classify the various plants according to their own methods (such as color, size, shape, structure, and taste). RFID technology can automatically and in real time determine the classification of students' activities and provide the corresponding feedback information, such as asking questions about the reasons and basis for classification when the classification is correct. Figure 4 presents the feedback by RFID technology when one student classifies the potatoes, cabbage, kiwi fruit, and lotus root.
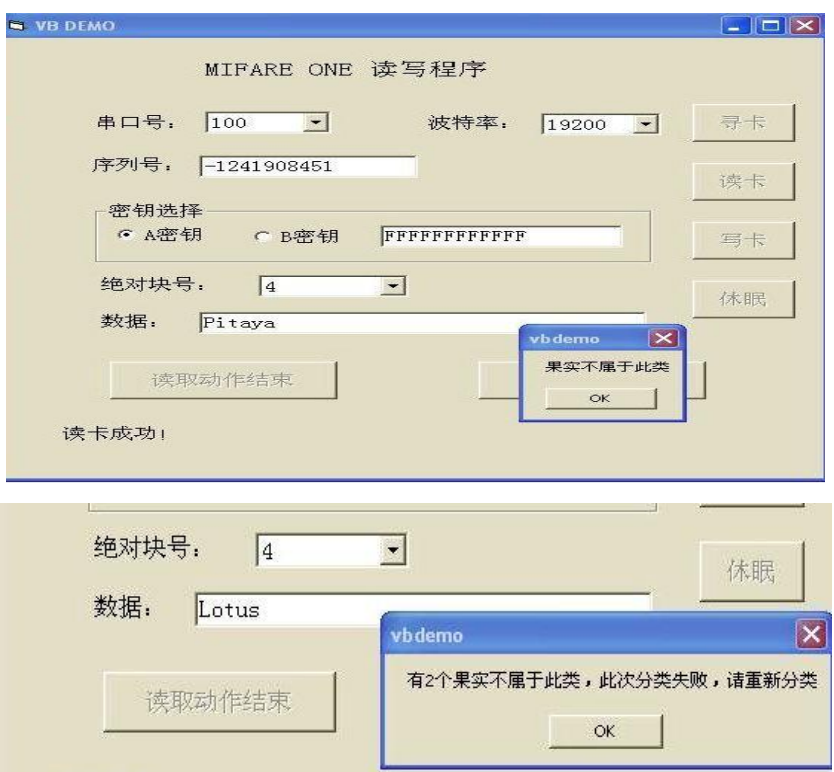

读卡成功!

Fig. 4. Classification feedback of a student activity 
(3) Classification of plants - After students recognize a variety of classifications in the two activities, they can classify the plants by their structure, such as roots, stems, leaves, fruits, and flowers. The RFID reader can sense this, and the system will automatically determine the students' categories and provide the results of information (Figure 5). The students' behavior in the activities can be recorded by card in a similar way.

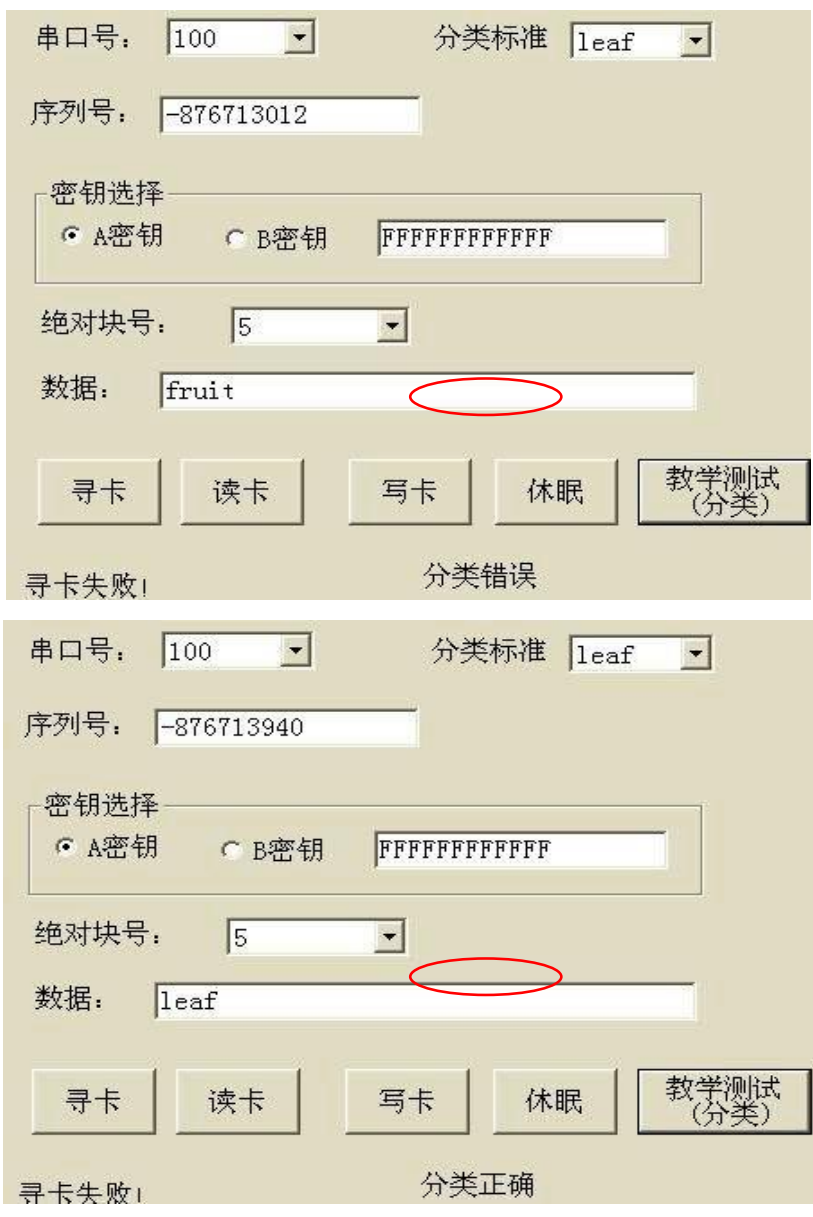

Fig. 5.Classification of plants according to their structure

Hence, under the process of teaching "the classification of plants," students can access the appropriate resources through the RFID system, which is suited to the creation of an environment based on real things which can be explored. Should the students find difficulties in problem solving, the system can find partnerships with other learners by internet according to the needs of students. At the same time, the system can record students' real-time learning activities, which facilitates their reflection and evaluation.

\section{RFID AS A Viable Means of Understanding The NATURE OF SCIENCE}

Currently, the understanding of the nature of science is becoming the thrust of science education. For instance, the scientific literacy being pushed by the National Science Education Standards includes the understanding of the nature of science. Such understanding the nature of science is also emphasized in our science (physics, chemistry, and biology) curriculum standards. The "history of science and the nature of science" being listed separately in Shanghai's science curriculum standard, which highlights the concerns of the nature of science and its teaching, clearly attest to that. Many scholars describe the nature of science from multidimensional aspects. Millar, J.D. has pointed out that it is necessary to understand the nature of scientific knowledge to develop students' sensitivity to the social issues of science. Meanwhile, Driver provided an important contribution to the understanding the nature of science: "make clear reflection on the nature of scientific knowledge, observation and experiment, the nature of theory, the relationship between evidence and theory" [10].

Hence, it has become the focus of attention for science education researchers and teachers to find ways on how to enhance students' understanding of the nature of science through the practice of teaching the subject. By recognizing the relationship between scientific inquiry and the nature of science, we can create scientific inquiry activities to guide students in understanding the nature of science through exploration activities. Taking the "classification of plants" as an example, we can use RFID technology to guide students in experiencing the three-level exploration activities to understand the various methods of classifying plants and eventually understand the nature of plant classification in the classified activities according to structure. This means that students can achieve the understanding of the nature of scientific knowledge. The process of exploring a variety of activities can also enable them to experience the essence of scientific inquiry method. With regard to the practice of teaching the nature of science, some scholars use the value of history to present the history of science, technical progress, and social impacts in relation with other subjects. It is helpful to highlight the scientists engaged in the process of scientific inquiry methods and present their ideas, which can be enhanced to the philosophical aspect of science; the most typical scholar is Matthews, who is an Australian expert in history, philosophy of science, and science education. Taking "the pendulum" as an example [11], Matthews - based on a variety of ancient Greece and medieval timing methods (such as a sundial, water clock, and monasteries timekeeping) and structural analysis of the clock, Galileo's pendulum clock and his analysis of pendulum motion, Huygens' innovative analysis of Galileo's pendulum theory, and the pendulum of Newtonian mechanics - pondered on the relationship between science and history, and thought of ways on how to teach about time and the pendulum. Based on the history of science - the history of the trace of science (pendulum) and technology (timing tools and its structure) -methodological thinking (the relationship of observation, theory, and experiment) provides basis for the teaching of history-based scientific inquiry of pendulum.

In middle school, the pendulum motion is inseparable from simple harmonic motion; since the cycloidal pendulum period formula is based on the deviation angle, which should be less than 5 degrees, the simple pendulum motion can be regarded as simple harmonic motion (force is proportional to the vibration displacement). Only under this condition can we gain pendulum cycle by tools for counting time. Matthews clearly mentioned that methods and tools are the key technologies. However, the improvement of timekeeping could not encourage students to accurately understand the 
conditions of simple pendulum. In teaching science, we often adopt similar computation, which means that $\sin \theta$ is similar to $\theta$ when the angle is small, to answer the question why the angle should be less than 5 degrees. It is, therefore, imperative for students to understand physical conditions by mathematical reasoning and approximation (it is difficult for students to understand abstract concepts, and the need for technology on "how to visualize and intuitively present the abstract mathematical reasoning" is put forward. We should know how to use technology to guide the students in understanding the problem on pendulum motion: "What is the harmonic vibration?" "What is the condition of simple harmonic motion?" "Which method can we use to measure the conversion of such movement patterns?" "Which physical quantity is needed?" "How do we measure the motion of the fork pendulum, stokes pendulum, and rocking movement relative to the simple pendulum motion?" Exploring all these issues would help in understanding the nature of simple pendulum.

The anti-collision characteristic of RFID, and its rapid reading time and time-keeping program make RFID suitable for use in science education ${ }^{6}$. However, given that the readable distance may be affected by the antenna position and orientation, the high-frequency (13.56 MHz) RFID reader is not an ideal option. It is more appropriate to choose the RFID reader with $\mathrm{CF}$ port. Considering its feature of having electromagnetic waves with high frequency, reflected waves with different intensity will be produced when the different surfaces (especially the metal surface) are encountered in the propagation media, which weakens the energy carried to reach the electronic tags and affect the data and information collection. Hence, we chose a non-metallic material such as a small ball (if the choice of material cannot be avoided, high-conductivity oxygen magnets can be used to absorb the electromagnetic wave isolation material, which can in turn absorb high-frequency gain of $24 \mathrm{~dB}$ ). Based on the real-time readings and recordings of pendulum motion (such as the instantaneous speed) process, students can use the recorded data and image information yielded by a PDA to analyze the entire motion and movement state change. After which, they can then determine and understand under what conditions (angle) can the pendulum be regarded as simple harmonic motion, and further assess the pendulum formula. At the same time, students can exchange information and ideas with one another, experience mutual evaluation and analysis to promote the understanding of the whole process of motion, and further explore the entire cycle. Similar to the nature of the pendulum, RFID technology can be applied to problem-solving processes closely related to energy conversion, which can help students understand the nature of such conversion.

In addition, with the development of RFID technology and

\footnotetext{
${ }^{6}$ Long-range RFID technology is used in sports timing solution with reading distance of $25-450 \mathrm{~cm}$ and collision avoidance capability, which can simultaneously identify 55 cards and attain $100 \mathrm{~km} / \mathrm{h}$ read speed. It can capture real-time data of athletes' laps, fastest lap time, and rank as well as show live games, and store game records [12].
}

in combination with other wireless sensor network technologies (such as ZigBee wireless sensor network), the reading distance can be increased from the original distance (less than $10 \mathrm{~m}$ ) to the effective radius of $100 \mathrm{~m}$. If RFID is combined with temperature labels ${ }^{7}$ such as vibration sensors and chemical sensors, its application can be broadened to be applied to science education.

In addition, with the development of RFID technology and in combination with other wireless sensor network technologies (such as ZigBee wireless sensor network), the reading distance can be increased from the original distance (less than $10 \mathrm{~m}$ ) to the effective radius of $100 \mathrm{~m}$. If RFID is combined with temperature labels ${ }^{8}$ such as vibration sensors and chemical sensors, its application can be broadened to be applied to science education.

\section{ACKNOWLEDGMENT}

We would like to thank the anonymous referees for providing us with constructive comments and suggestions.

\section{REFERENCES}

[1] X. Huang, Y. Y. Yeung, and S. C. Kong, "Review on Radio Frequency Identification Technology (RFID) in Education".e-EDUCATION RESEARCH, 11, pp.73-77,2009.

[2] Ministry of Science and Technology People's Republic of Fifteen Ministries, "China Radio Frequency Identification Technology (RFID) Policy White Paper", June 9. 2006.

http://www.eetchina.com/ARTICLES/2006JUN/PDF/CHINARFIDW HITEPAPER.PDF.2009-5-10.

[3] International Technology and Economy Institute of State Council Development Research Center, The National Radio Frequency Identification Industry (Shanghai) Base, Shanghai Zhangjiang Co. Ltd., "RFID Blue Book - Report of Frequency Identification (RFID) Technology Development and its Application in China", 2009.

[4] You Zhanqing etc. Radio Frequency Identification (RFID) and bar-code technology [M]. Machinery Industry Press, 2007: 285.

[5] Tan Ming, etc. engineering and application guide of RFID technology systems [M]. Machinery Industry Press, 2007:20-28.

[6] Kang Dong, etc. Radio Frequency Identification (RFID) technology and its' typical application cases [M]. People Post Press, 2008: 11-15.

[7] Y. Li, "Scientific Inquiry, Scientific Literacy and Science Education". Global Education, 12, pp.14-18, 2008.

[8] U.S. National Research Council, "The National Science Education Standards", Beijing: Science Academic Press, pp.30, 1999.

[9] X. Gao, "Scientific Inquiry Comparison in the Primary Science Textbooks of the U.S. and China", Nanjing Normal University, pp. 10-11, 2002.

[10] M. Ratcliffe, J. Osborne, S. Collins, R. Millar and R. Duschl. Evidence-based Practice in Science Education (EPSE). "Teaching Pupils 'Ideas-about-science': Clarifying Learning Goals and Improving Pupil Performance", Paper presented at the European Science Education Research Association Conference. Thessaloniki, Greece August 2001

http://eprints.soton.ac.uk/58277/01/esera_epse3_2001.pdf. 2009-11-1

[11] M. R. Matthews, "Time for Science Education: How Teaching the History and Philosophy of Pendulum Motion Can Contribute to Science Literacy", New York: Kluwer Academic/ Plenum Publishers, 2000.

[12] Games Time-keeping Program. http://www.matagid.com/ap_sports.htm. 2009-11-3.

\footnotetext{
${ }^{7}$ Such as the information disseminated by RFID World Network (2006-3-10): Germany-based company KSW is a semi-active (thin paper-like battery) RFID smart label sensor manufacturer. It announced a new integration of adhesive temperature sensor RFID smart labels VarioSens Basic - which can measure temperature of up to 720 degrees.
} 


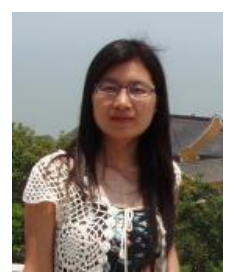

Xiao Huang, female, was born in Jinhua City, Zhejiang Province, China on July.30, 1978. She got bachelor degree on physics from the physics department of Zhejiang Normal University, 1999. Then, she got Master degree of physics education major from mathematics and Physics College of Zhejiang Normal University, 2002. Also, she got $\mathrm{PhD}$ of Science Education major from the East China Normal University in June, 2010. In 2008, she went to HKIED for cooperative research about RFID technology and education.

Act as an associate professor of East China Normal University and Zhejiang Normal University; she is a physics teaching Committee member of Zhejiang now. She has presided over several kinds of projects and published one book, about ten journal papers and several conference papers. Now she is principally interested in science education (such as) the nature of science teaching, integration information technology into science teaching.

Dr. Huangxiao has won the Outstanding Graduate Scholarship and outstanding doctoral Fund of the East China Normal University, have got the title of outstanding instructor by the National Physical Education Committee. And she is also a member of IEEE and IACSIT

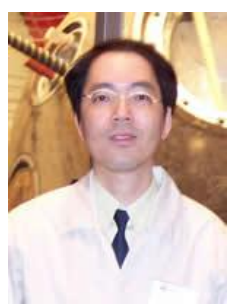

Dr. Yau-yuen Yeung is associate head and associate professor in the Department of Science and Environmental Studies, Hong Kong Institute of Education. Apart from being the programme leader of the Bachelor of Science Education (Honours)(Science \& Web Technology), he supervises Doctor of Education and $\mathrm{PhD}$ candidates. He is a senior member of the Association for Computing Machinery (USA) and a chartered Physicist of the Institute of Physics (UK). Besides, he is the founding and current Chie Editor of the refereed journal called "Asia-Pacific Forum on Science Learning and Teaching" (ISSN 1609-4913) (2000-now), past Secretary of the Asia-Pacific EPR/ESR Society (1997-2004) and adjunct professor of the East China Normal University (Shanghai, China) (2008-2011).

His current research interest includes scientific computation in condensed matter physics, information technology in education, science education and social network analysis in education.

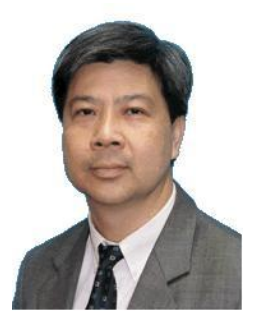

Siu Cheung Kong, male, Head of Department and Associate Professor of the Department of Mathematics and Information Technology, the Hong Kong Institute of Education, Hong Kong. Dr Kong holds a doctorate from the Department of Computer Science of the City University of Hong Kong. Dr. Kong has published 15 books/proceedings, 15 refereed book chapters, 32 refereed journal articles and 50 refereed conference papers.

Dr. Kong is at present serving as the Editor-in-Chief of the internationa journal Research and Practice in Technology Enhanced Learning (RPTEL) and the member of several editorial review boards in international journals related to computers in education. Dr. Kong served as a member of the Steering Committee on the Strategic Development of Information Technology in Education that was set up by the Education Bureau of the HKSAR for six years from 2003 to 2009. He is now member of the Assessment and Monitoring Sub-committee of the Quality Education Fund (QEF) of the HKSAR.

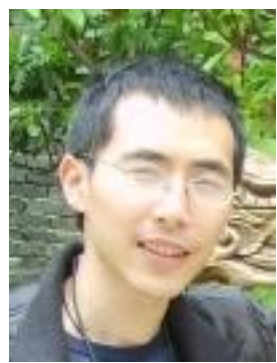

Wei Gao, male, was born in the city of Shaoxing, Zhejiang Province, China on Feb.13, 1981. He got two bachelor degrees on computer science from Zhejiang industrial university in 2004 and mathematics education form College of Zhejiang education in 2006. Then, he enrolled in department of computer science and information technology, Yunnan normal university, and got Master degree from there in 2009. Now, he is $\mathrm{PhD}$ student in college of Mathematics, Soochow University, China.

During the school years in Soochow University, he also acts as lecturer in the department of information, Yunnan Normal University. As a researcher in computer science and mathematics, his interests are covered two disciplines: Graph theory, Statistical learning theory, Information retrieval, and artificial intelligence. 